\title{
ÇEMEN OTU TOHUMUNDAN FENOLİK BİLEŞENLERİN EKSTRAKSIYYONU İÇİN OPTİMİZASYON ÇALIŞMASI
}

\author{
Sedanur Daştan, İzzet Türker, Hilal İşleroğlu* \\ Tokat Gaziosmanpaşa Üniversitesi, Mühendislik ve Mimarlık Fakültesi Gıda Mühendisliği Bölümü, Tokat, \\ Türkiye
}

Geliş / Received: 14.04.2021; Kabul / Accepted: 07.06.2021; Online bask1 / Published online: 02.07.2021

Daştan, S., Türker, İ., İşleroğlu, H. (2021). Çemen otu tohumundan fenolik bileşenlerin ekstraksiyonu için optimizasyon çalışması. GIDA (2021) 46 (4) 959-970 doi: 10.15237/gida.GD21071.

Daștan, S., Türker, I., Issleroğlu, H. (2021). An optimization study on the extraction of phenolic compounds from fenugreek seeds. GIDA (2021) 46 (4) 959-970 doi: 10.15237/gida.GD21071.

ÖZ

$\mathrm{Bu}$ çalışmada, çemen otu (Trigonella foenum-graecum L.) tohumundan saf su kullanılarak farklı sıcakliklarda mekanik karıştırma ile fenolik ekstraktlar elde edilmiştir. Ekstraktların toplam fenolik madde (TFM), toplam flavonoid (TFL) ve antioksidan kapasiteleri (AK) üzerine ekstraksiyon sicaklı̆̆ $\left(30-80^{\circ} \mathrm{C}\right)$, ekstraksiyon süresi (10-120 dakika) ve karıştırma hızının (3600-20000 rpm) etkileri incelenmiştir. TFM, TFL ve AK'nin en yüksek değerlere ulaşabilmesi için optimum işlem koşulları Merkezi Kompozit Tasarım kullanılarak 'desirability' fonksiyonu yaklaşımı ile belirlenmiştir. Optimizasyon sonuçlarına göre, $45^{\circ} \mathrm{C}$ ekstraksiyon sıcaklı̆̆1, 65 dakika ekstraksiyon süresi ve $20000 \mathrm{rpm}$ karıştırma hızında ekstraktların TFM içeriği $137.37 \pm 1.87 \mathrm{mg}$ gallik asit/g kuru örnek, TFL içeriği $86.96 \pm 1.44 \mathrm{mg}$ kuersetin/g kuru örnek ve AK'si $18.11 \pm 0.55 \mathrm{mM}$ Trolox/g kuru örnek olarak belirlenmiştir. Çemen otu tohumu ekstraktlarının, yüksek fenolik madde içeriği ve antioksidan kapasitesi ile farklı gida formülasyonlarında kullanım potansiyeline sahip olduğu düşünülmektedir.

Anahtar kelimeler: Çemen otu tohumu, mekanik karışturma, toplam fenolik madde, toplam flavonoid, antioksidan kapasite, optimizasyon

\section{AN OPTIMIZATION STUDY ON THE EXTRACTION OF PHENOLIC COMPOUNDS FROM FENUGREEK SEEDS}

\begin{abstract}
In this study, phenolic compounds (PCs) were extracted from fenugreek seeds (Trigonella foenumgraecum L.) by mechanical agitation using pure water at different temperatures. The effects of the extraction temperature, extraction time, and agitation rate on the total PCs (TPCs), total flavonoids (TFLs), and antioxidant capacities (ACs) of the extracts were investigated. Optimum conditions for which TPCs, TFLs, and ACs reached their highest value were determined using the desirability function of the central composite design. Optimization results at $45^{\circ} \mathrm{C}$ extraction temperature, 65 min extraction time, and $20000 \mathrm{rpm}$ agitation rate showed that TPCs were $137.37 \pm 1.87 \mathrm{mg}$ gallic $\mathrm{acid} / \mathrm{g}$ dry sample, TFLs were $86.96 \pm 1.44 \mathrm{mg}$ quercetin/g dry sample, and ACs were $18.11 \pm 0.55$
\end{abstract}

\footnotetext{
* Yazışmalardan sorumlu yazar / Corresponding author

$\triangle$ : hilal.isleroglu@gop.edu.tr $\quad$ (D):(+90) 356252 1616/2888

且:(+90) 3562521729

Sedanur Daştan; ORCID no: 0000-0003-1393-5270

İzzet Türker; ORCID no: 0000-0003-0107-1962

Hilal İşleroğlu; ORCID no: 0000-0002-4338-9242
} 
$\mathrm{mM}$ Trolox/g dry sample. The fenugreek seed extracts having high amounts of phenolic compounds and high antioxidant capacity are believed to have the potential for use in different food formulations. Keywords: Fenugreek seeds, mechanical agitation, total phenolic compounds, total flavonoid, antioxidant capacity, optimization

\section{GİRİ̧̧}

Çemen otu tohumu sert köşeli, pürüzlü ve esmer kırmızı görünüme sahip Trigonella foenum-graecum $\mathrm{L}$. (Leguminosae) bitkisinin içerisinde yer alan bir tohumdur. Kokusuz olan tohumunun ögütülmüss hali 3-Hydroxy-4,5-Dimethyl-2(5H)-Furanon bileşiği sayesinde kuvvetli bir kokuya sahiptir (Baytop, 1984). Çemen otu tohumu fenolik maddeler, diyet lifi, protein, yağ, azotlu bileşikler, çeşitli mineraller ve vitaminler bakımından oldukça zengin bileşime sahip bir üründür. Zengin bileşiminden dolayı çemen otu tohumunun insan sağllğ1 üzerinde önemli ve olumlu etkilere sahip olduğu bilinmektedir (Srinivasan, 2006; Dixit vd., 2005).

Çemen otu tohumunun ekstraksiyonu sonucu elde edilen fenolik ekstraktların önemli oranda antioksidan madde içerdikleri bilinmektedir. Çemen otu tohumunda viteksin, trisin, narinjenin, kuersetin ve luteolin gibi flavonoidlerin varlığ yapılan çalışmalar ile tespit edilmiştir (Khorshidian vd., 2016). Aynı zamanda yapilan çalışmalar ile çemen otu tohumu fenolik ekstraktlarının, askorbik asit, glutatyon, $\beta$-karoten, alfa tokoferol gibi antioksidan etkiye sahip molekülleri içerdiği de bulgulanmıştır (Kenny vd., 2013; Yadav ve Chowdhury, 2017).

Zengin bileşime sahip çemen otu tohumu, uluslararası ticarette gida sanayinde kullanılmak üzere lezzet verici ve doğal antibakteriyel ürün olarak kendine yer bulmaktadır. Bunlara ek olarak birçok ürünün formülasyonunda kullanım potansiyeline sahiptir. Ayrıca pastırma yapımında kullanılan kaplamanın da temel bileşenlerinden biridir. Çemen otu tohumundan sağlık alanında ise tahriş giderici, bağırsak yumuşatıcı, gaz giderici, sindirimi kolaylaştırıcı, süt artırıcı olarak yararlanılmaktadır (Abdelgani vd., 1999; Dixit vd., 2005; Gökçe ve Efe, 2016).

Fenolik maddeler, bitkilerde aromatik aminoasit metabolizmasi sirasinda sentezlenen yan bileşiklerden oluşan ikincil metabolitlerdir ve flavonoidler, lignanlar, stilbenler ve tanenler olarak sinıflandırılmaktadır (Atak ve Uslu, 2018). Fenolik maddeler tat ve koku oluşumundaki etkileri, renk oluşumu ve değişimine katılmaları, antimikrobiyal ve antioksidatif etki göstermeleri, enzim inhibisyonuna neden olmalar1 sebebiyle oldukça önemli gida bileşenleri olarak değerlendirilirler (Hakkinen, 2000; Tenderis, 2010; Atak ve Uslu, 2018). Fenolik maddelerin alt gruplarından biri olan flavonoidlerin ise tüketildiklerinde özellikle kanser ve kalp rahatsızlıklarının yayılma hızlarını azalttıkları bilinmektedir (Ignat vd., 2011; Birman, 2012). Sağlık açısından etkileri düşünüldüğünde, doğal ürünlerde bulunan fenolik bileşikler gibi biyoaktif bileşenlerin yüksek verimde ekstraksiyonu üzerine birçok araştırma yapılmaktadır. Çemen otu tohumunun bileşimi göz önünde bulundurulduğunda ise çemen otu tohumundan elde edilecek sulu ekstraktların fenolik bileşik açısından zengin olacağ1 ve bu ekstraktların farklı gidalarda kullanılabileceği düşünülmektedir. Dünyada ve Türkiye'nin çeşitli bölgelerinde yetiştiriciliği yapılan çemen otu tohumundan fenolik madde ekstraksiyonu ile ilgili literatürde çalısmalar bulunmaktadır (Belguith-Hadriche vd., 2013; Kenny vd., 2013; Al-Juhaimi vd., 2016). Ancak yapılan literatür araştırmasında, çemen otu tohumlarından fenolik ekstrakt elde edilebilmesi amacıyla farklı sıcaklıklarda karıştırma işleminin uygulandığı ve işlem parametrelerinin ekstraktta bulunan fenolik maddelerin miktarı üzerine etkilerinin incelenerek optimizasyonunun gerçekleştirildiği bir çalışmaya rastlanmamıştır.

Fenolik maddeler gibi biyoaktif bileşenlerin ekstraksiyon koşullarından önemli oranda etkilendiği yapılan çalışmalar ile ortaya konulmuştur. Ekstraksiyon verimini en fazla etkileyen parametreler çözgen çeşidi, çözgen konsantrasyonu, ekstraksiyon süresi, ekstraksiyon sıcaklığ1 ve karıştırma hızı olarak bildirilmiştir (Goli vd., 2005; Belguith-Hadriche vd., 2013; Ballard vd., 2009; Zuorro vd., 2016). Literatürde, ekstraksiyon sicaklığının artması ile fenolik 
maddelerin ekstraksiyon veriminin arttı̆̆ını bildiren çalışmalar bulunmaktadır (Benmeziane vd., 2014; Dorta vd., 2012). Yang vd. (2009), gardenya meyvesinden fenolik madde ekstraksiyonunda ekstraksiyon sicaklı̆̆ındaki artışın fenolik madde ekstraksiyonuna doğrusal olarak etki ettiğini bildirerek yaptıkları çalışmada optimum ekstraksiyon sicaklığın $73^{\circ} \mathrm{C}$ olarak tespit etmişlerdir. Mokrani ve Madani (2016), şeftali ile ilgili yaptıkları ekstraksiyon çalışmasında ise farklı ekstraksiyon sicaklıklarının fenolik madde ekstraksiyonunu önemli ölçüde etkilediğini belirtmişlerdir. Sıcaklığın artması ile birlikte toplam fenolik madde veriminin düştüğünü, bununla birlikte sıcaklığın artışına bağlı olarak toplam flavonoid veriminin arttığını gözlemlemişlerdir. Sıcaklık, bitki dokusunun yumuşamasina ve fenol-protein ve fenolpolisakarit etkileşimlerin zayıflamasına ve böylece daha fazla polifenolün çözücüye geçmesine neden olabilmektedir. Benzer şekilde genellikle glikozit yapıda olan ve bitki dokularında bulunan flavonoidlerin, ekstraksiyon sıcaklığının belirli bir düzeye kadar artırılması ile ekstraksiyon verimlerinin arttığı bildirilmiştir (Mokrani ve Madani 2016). Bazı çalışmalarda ise sıcaklık artışının belli bir noktadan sonra fenolik maddeler üzerinde olumsuz etki yaparak azaltma eğilimine neden olduğu sonucuna varılmıştır (Silva vd., 2007; Sun vd., 2011; Yim vd., 2011; Ballard vd., 2009).

$\mathrm{Bu}$ çalışmanın amacı, çemen otu tohumunda bulunan fenolik maddelerin mekanik karıştırma işlemi ile farklı sıcaklıklarda ve sürelerde ekstraksiyonunun sağlanması ve en yüksek fenolik madde ekstraksiyonunun sağlandığ1 optimum işlem koşullarının tespit edilmesidir.

\section{MATERYAL VE YÖNTEM}

\section{Materyal}

Çalışmada Tokat ilinde yetiştirilmiş çemen otu (Trigonella foenum-graecum L.) bitkisinin tohum kısımları kullanılmıştır. Tohumlar bir blender (Sinbo SHB 3020, Türkiye) yardımı ile toz hale getirilmiş ve $630 \mu \mathrm{m}$ gözenek çapına sahip elek kullanilarak elek altında kalan toz örnekler toplanmıştır. Kullanıma hazır hale getirilen toz tohum örnekleri analizler yapilıncaya kadar oda sıcaklığında karanlık bir ortamda depolanmıştır.

\section{Ekstraksiyon işlemi ve Optimizasyon}

Toz forma getirilmiş çemen otu tohumu örneklerinden fenolik maddelerin ekstraksiyonu amac1 ile çözgen olarak yalnızca saf su kullanılmıştır. Yapılan ön denemeler ile toz örnek/saf su karışım oranı $0.5 \mathrm{~g} / 50 \mathrm{~mL}$ olarak belirlenmiş ve tüm koşullarda sabit tutulmuştur. Ekstraksiyon işlemi için mekanik bir homojenizatör (IKA-Works, Ultra Turrax T-18 Basic, Almanya) kullanılmış ve farklı karıştırma hizlar1 (3600, 11200 ve $20000 \mathrm{rpm}$ ) ve sicakliklarda $\left(30,55\right.$ ve $\left.80^{\circ} \mathrm{C}\right)$ ekstraksiyon işlemleri gerçekleştirilmiştir. En yüksek toplam fenolik madde (TFM), toplam flavonoid (TFL) ve antioksidan kapasite (AK) değerlerini sağlayacak olan ekstraksiyon koşullarının optimizasyonu 'Merkezi Kompozit Tasarım (Central Composite Design)' kullanılarak gerçekleştirilmiştir. Çalışmada kullanılan deneysel tasarım Çizelge 1'de gösterilmiştir. Ekstraksiyon işlemlerinde ekstraksiyon yöntemine özgü işlem değişkenlerinin TFM, TFL ve AK üzerine etkisi incelenerek en yüksek değerlere sahip ekstrakt eldesini sağlayacak ekstraksiyon işlemi 'desirability' fonksiyon yaklaşımına göre optimize edilmiştir. Oluşturulan matematiksel modellere göre ekstraksiyon verimi için modeldeki anlamlı terimler varyans analizi ile belirlenmiştir. Ekstraksiyon işlemleri sonucunda elde edilen yanıtların regresyon analizi için Eşitlik (1)'de verilen model kullanılmıştır.

TFM, TFL ve $A K=\beta_{0}+\sum_{i=1}^{k} \beta_{i} X_{i}+$

$\sum_{\mathrm{i}=1}^{k} \beta_{\mathrm{i}} \mathrm{X}_{\mathrm{i}}^{2}+\sum_{\mathrm{i}=1}^{k-1} \sum_{\mathrm{j}=\mathrm{i}+1}^{k} \beta_{\mathrm{ij}} \mathrm{X}_{\mathrm{ij}} \quad k=1,2$

Eşitlikte $\beta_{0}$ sabit katsayıyı, $\beta_{i}$ i’inci gözlemin katsayısını, $\beta_{\mathrm{ij}}$ i'inci gözlemin j'inci katsayısını, $k$ bağımsız değişken sayısını, $X_{i}$ i'inci bağımsız değişkeni, $X_{i j}$ ise i’inci gözlemin j’inci bağımsız değişkenini ifade etmektedir.

Ekstraksiyon işlemleri gerçekleştirildikten sonra örneklerin analizlerde kullanılabilir hale getirilebilmesi için elde edilen süspansiyonlara öncelikle $6000 \mathrm{rpm}$ ve 5 dakika süre ile santrifüj işlemi uygulanmıştır (Hettich EBA 21, Almanya). 
Sonrasinda süpernatant faz kaba filtre kâğıdı ile süzülerek toplanmış ve analizler süpernatant fazlar kullanılarak gerçekleştirilmiştir.

\section{Toplam fenolik madde tayini}

Örneklerin TFM miktarları Folin-Ciocalteau yöntemi ile belirlenmiştir. Folin-Ciocalteau çözeltisi, $\mathrm{Na}_{2} \mathrm{CO}_{3}$ ve örnekleri içeren karışımlar 25 dakika süre ile oda sıcaklığında ve karanlıkta bekletildikten sonra $3800 \mathrm{rpm}$ ve 10 dakika süre ile santrifüj işlemine tabi tutulmuştur. Süpernatant fazların $725 \mathrm{~nm}$ dalga boyunda absorbanslan okunarak (P\&G Instruments T80+, Birleşik Krallık) TFM miktarları gallik asit (Sigma-Aldrich, Almanya) ekivalanı (mg gallik asit /g kuru örnek) cinsinden ifade edilmisstir (Claus vd., 2015).

\section{Toplam Flavonoid tayini}

Örneklerin TFL miktarı alüminyum klorür yöntemi kullanarak spektrofotometrik olarak belirlenmiştir. Örneklerin absorbans değerleri 510 nm'de okunarak TFL miktarları kuersetin (BLD Pharmatech Ltd., Çin) ekivalanı (mg kuersetin/g kuru örnek) cinsinden hesaplanmıştır (Gaafar ve Salama, 2013).

\section{Antioksidan kapasite tayini}

Örneklerin antioksidan kapasitesi 2,2-Difenil-1pikrilhidrazil (DPPH) radikal söndürücü kapasite yöntemi ile belirlenmiştir. DPPH (Sigma-Aldrich, Almanya) çözeltisi ile karıştırılan örnekler 30 dakika süre ile oda sıcaklığında karanlıkta bekletilerek $515 \mathrm{~nm}$ dalga boyunda absorbansları okunmuştur. Antioksidan kapasite trolox (SigmaAldrich, Almanya) cinsinden (mM Trolox/g kuru örnek) ifade edilmiştir (Brand-Williams vd., 1995).

\section{İstatistiksel analiz}

İstatistiksel analizler SPSS 22.0 ve Design Expert 7.0 paket programlar1 kullanilarak gerçekleştirilmiştir. Tahminlenen değerler ile deneysel veriler arasında fark olup olmadığını belirlemeye yönelik tek örnek t-testi ve örnekler arasındaki Pearson katsayılarının hesaplanması SPSS 22.0 paket programı kullanılarak, işlem değişkenlerinin TFM, TFL ve AK üzerine etkisini belirlemede uygulanan regresyon analizi, istatistiksel analizler, izohips grafikleri, yanıt yüzey grafikleri ve optimizasyon işlemleri Design Expert
7.0 (Stat-Ease Inc., ABD) paket program1 kullanılarak gerçekleştirilmiştir.

\section{SONUÇ VE TARTIŞMA}

Deneysel tasarımda belirlenen tüm koşullar için uygulanan ekstraksiyon işlemleri sonucunda elde edilen sonuçlar Çizelge 1'de verilmiştir. Elde edilen ekstraktların TFM değerleri 21.01-136.33 mg gallik asit/g kuru örnek, TFL değerleri 12.31$88.26 \mathrm{mg}$ kuersetin/g kuru örnek ve AK değerleri 2.69-17.67 mM Trolox/g kuru örnek aralığında belirlenmiştir. Çemen otu tohumu ile yapılan ekstraksiyon çalışmaları incelendiğinde, metanol, etil asetat ve etanol gibi organik çözgenler kullanılarak 78.1-85.9 mg gallik asit/g kuru örnek TFM içeren ekstraktlar elde edildiği görülmüştür (Belguith-Hadriche vd., 2013; Kenny vd., 2013). Ayrıca, literatürde çemen otu tohumunun TFL içeriğini yalnızca saf su kullanarak belirleyen bir çalışmada TFL değeri $17.49 \mathrm{mg}$ kuersetin/g kuru örnek olarak tespit edilmiştir ve çemen otu tohumunda TFM içeriğinin yaklaşık \%37'sinin TFL olduğu bildirilmiştir (Dixit vd., 2005). Farklı bir çalışmada, çemen otu tohumunun yetiştiği bölgenin iklim koşullarına bağlı olarak $100 \mathrm{mg} / \mathrm{g}$ kuru örnek düzeyine kadar flavonoid içerebileceği belirtilmiştir (Gupta ve Nair, 1999). Bu çalışmada ise $55^{\circ} \mathrm{C}$ ekstraksiyon sicaklığı, 65 dakika ekstraksiyon süresi ve $20000 \mathrm{rpm}$ karıştırma hızında $88.26 \mathrm{mg}$ kuersetin/g kuru örnek düzeyinde TFL elde edilmiştir. Tüm koşullarda örneklerin TFL içeriği TFM içeriğinin ortalama olarak yaklaşık \%60'ını oluşturmaktadır.

Elde edilen sonuçlara göre, $80^{\circ} \mathrm{C}$ 'de yapılan ekstraksiyon işlemlerinde TFM, TFL ve AK değerlerinin, 30 ve $55^{\circ} \mathrm{C}$ 'de gerçekleştirilen ekstraksiyon işlemlerine kıyasla daha düşük olduğu bulgulanmıştır (Çizelge 1). Bu durumun yüksek sicaklığın baz1 flavonoidler üzerine olumsuz etkisinden ileri geldiği düşünülmektedir. Benzer şekilde Silva vd. (2007), Inga edulis yapraklarından fenolik madde ekstraksiyonu gerçekleştirdikleri çalışmada flavonoid veriminin olumsuz etkilenmediği en yüksek ekstraksiyon sıcaklığını $62.5^{\circ} \mathrm{C}$ olarak belirlemişlerdir.

Çizelge 1 incelendiğinde, genel olarak 10 dakikalık ekstraksiyon işleminin TFM, TFL ve AK değerlerinin en yüksek seviyede elde edilmesi için 
yeterli olmadığ1 görülmektedir. Buna karşın, yüksek karıştırma hızında 10 dakikalık ekstraksiyon işlemi ile TFM, TFL ve AK değerlerinde artış olduğu gözlenmiştir. Yüksek karıştırma hızlarında sağlanan mekanik etki ile fenolik bileşenlerin hücre çeperinden çıkması daha kolay olabilmekte ve böylece daha yüksek TFM içeriğine sahip ekstraktlar elde edilebilmektedir. Çizelge 1'de en yüksek TFM, TFL ve $A K$ değerlerinin en yüksek karıştırma hizinda (20000 rpm), $30-55^{\circ} \mathrm{C}$ ekstraksiyon sicaklıklarında ve 65 dakikalık ekstraksiyon süresinde elde edildiği görülmektedir. Ekstraktların fenolik madde içeriğine etki eden parametrelerden ekstraksiyon süresi, optimizasyon işlemleri için büyük önem taşır. Elde edilen sonuçlara göre, 30 ve $55^{\circ} \mathrm{C}$ 'de gerçekleşen 120 dakikalık ekstraksiyon işleminin 65 dakikalık ekstraksiyon işlemine oranla TFM, TFL ve AK değerlerini düşürücü yönde etkisi olduğu tespit edilmiştir. Karıştırma hızının artması ile çözgen damlacıklarının boyutu küçülür ve katı faz ile çözgen arasındaki temas yüzeyi artış gösterir. Ayrıca, yüksek hızda mekanik karıştırma işlemi hücresel yapıları bozan mekanik bir isslem olarak tanımlanır ve hücre içinde bulunan, mekanik etki olmaksızın çözgene geçmesi mümkün olmayan hücre bileşenlerinin (baz1 fenolik maddeler vb.) geçişini kolaylaştırır (Zhu vd., 2016; Javaldi, 2020). Bu doğrultuda, çalışmada uygulanan 20000 rpm karıştırma hızında en yüksek TFM, TFL ve AK değerleri elde edilmiştir. Yapılan çalışmada, TFM-TFL ve TFM-AK değerleri arasında pozitif bir korelasyon olduğu görülmektedir ve korelasyon katsayıları sırasiyla 0.997 ve 0.995 olarak hesaplanmıştır $(P<0.05)$.

Gerçekleştirilen ekstraksiyonlarda işlem değişkenlerinin TFM, TFL ve AK değerleri üzerine etkisi varyans analizi (ANOVA) çizelgesi ile verilmiştir (Çizelge 2). Her üç analiz için oluşturulan kuadratik modeller istatistiksel olarak $\% 99$ seviyesinde anlamlidır $(P<0.01)$ ve model uygunsuzluğu \%95 güven seviyesinde istatistiksel olarak anlamsızdır ( $P$ >0.05) (Çizelge 2). Oluşturulan modellerin deneysel verileri yüksek doğruluk ile açıklayabilmesi için gereken kriterlerden biri, model uygunsuzluğu verilerinin istatistiksel olarak önemsiz bulunmasıdır (Myers ve Montgomery, 1995) ve yapılan çalışmada model uygunsuzluğu verilerinin istatistiksel olarak önemsiz olması ( $P>0.05)$, TFM, TFL ve AK için oluşturulan ikinci dereceden polinomiyal modellerin başarısını ortaya koymaktadır.

Sonuçlara göre, TFM, TFL ve AK için oluşturulan modellerde her bir işlem değişkeninin doğrusal ve kuadratik etkileri \%99 seviyesinde anlamlıdır ( $P$ $<0.01$ ) (Çizelge 2). Buna karşın ekstraksiyon sıcaklığı-karıştırma hızı interaksiyonunun TFM, TFL ve AK modelleri üzerinde istatistiksel olarak anlaml herhangi bir etkisi bulunmamaktadır ( $P$ $>0.05$ ) (Çizelge 2).

Model uygunsuzluğu değerlerine ek olarak, modelin deneysel verileri ne ölçüde karşıladığı $\mathrm{R}^{2}$, düzeltilmiş $\mathrm{R}^{2}$ (Düz- $\mathrm{R}^{2}$ ), yeterli tahminleme, tahminlenmiş kalıntı hata kareler toplamı (PRESS) ve varyasyon katsayıs1 C.V. (\%) ile belirlenmiştir (Çizelge 3). Oluşturulan modellerin tümü için varyasyonun oldukça önemli bir kısmı model tarafından açıklanabilmiştir $\left(\mathrm{R}^{2}>0.99\right)$. Buna karşın modele eklenebilecek yeni terimlerin her zaman $\mathrm{R}^{2}$ değerini artırma eğiliminde olması nedeniyle, model uygunluğunun ifadesinde Düz$\mathrm{R}^{2}$ değerlerinin kullanılması önerilir (Myers ve Montgomery, 1995). Sonuçlara göre, TFM, TFL ve $A K$ için oluşturulan modellerde $R^{2}$ ve Düz- $R^{2}$ değerleri birbirine oldukça yakın olarak belirlenmiştir (Çizelge 3) ve bu durum modellerin istatistiksel olarak önemsiz terimleri içermediğini göstermektedir.

Ekstraksiyon işlemleri için oluşturulan ve optimizasyon çalışmasında regresyon analizi ile elde edilen ikinci dereceden polinomiyal modeller TFM için Eşitlik (2), TFL için Eşitlik (3) ve AK için Eşitlik (4) ile verilmiştir (20000 rpm karıştırma hızı için). Ek olarak, en yüksek değerlerin sağlandığ $20000 \mathrm{rpm}$ karıştırma hızı sabit tutularak ekstraksiyon sicakliğ1 ve ekstraksiyon süresi parametrelerinin TFM, TFL ve AK üzerine etkisini gösteren 3D Yanit Yüzey Grafikleri Şekil 1'de gösterilmiştir. Ayrıca, deneysel veriler ile modellerden tahminlenen veriler arasındaki ilişki Şekil 2'de verilmiştir. 
TFM (mg gallik asit/g kuru örnek $)=+18.94+4.08 \mathrm{X}_{1}+0.86 \mathrm{X}_{2}+3.98 \times 10^{-3} \mathrm{X}_{1} \mathrm{X}_{2}-0.05 \mathrm{X}_{1}^{2}-7.47 \times 10^{-3} \mathrm{X}_{2}^{2}$ TFL (mg kuersetin/g kuru örnek) $=+10.69+2.67 \mathrm{X}_{1}+0.55 \mathrm{X}_{2}+2.72 \times 10^{-3} \mathrm{X}_{1} \mathrm{X}_{2}-0.03 \mathrm{X}_{1}^{2}-4.85 \times 10^{-3} \mathrm{X}_{2}^{2}$ $\mathrm{AK}(\mathrm{mM}$ Trolox $/ \mathrm{g}$ kuru örnek $)=+2.75+0.52 \mathrm{X}_{1}+0.11 \mathrm{X}_{2}+5.18 \times 10^{-4} \mathrm{X}_{1} \mathrm{X}_{2}-6.30 \times 10^{-3} \mathrm{X}_{1}^{2}-9.97 \times 10^{-4} \mathrm{X}_{2}^{2}$

Çizelge 1. Deneysel tasarım ve elde edilen toplam fenolik madde, toplam flavonoid ve antioksidan kapasite değerleri

Table 1. Experimental design and obtained total phenolic compounds, total flavonoid and antioxidant capacity values

\begin{tabular}{|c|c|c|c|c|c|c|}
\hline Deneme No. & $\begin{array}{c}\text { Ekstraksiyon } \\
\text { Sicakliğ1 } \\
\left({ }^{\circ} \mathrm{C}\right)\left(\mathrm{X}_{1}\right) \\
\text { Extraction } \\
\text { Temperature }\left({ }^{\circ} \mathrm{C}\right) \\
\left(\mathrm{X}_{1}\right)\end{array}$ & $\begin{array}{c}\text { Ekstraksiyon } \\
\text { Süresi } \\
\text { (dak) }\left(\mathrm{X}_{2}\right) \\
\text { Extraction } \\
\text { Time } \\
\text { (min) }\left(X_{2}\right)\end{array}$ & $\begin{array}{l}\text { Karıştırma Hızı } \\
(\text { rpm })\left(\mathrm{X}_{3}\right) \\
\text { Agitation Rate } \\
(\text { rpm })\left(X_{3}\right)\end{array}$ & $\begin{array}{c}\text { TFM } \\
\text { (mg gallik asit/g } \\
\text { kuru örnek) } \\
\text { TPC (mg gallic } \\
\text { acid/g dry sample) }\end{array}$ & $\begin{array}{c}\text { TFL } \\
\text { (mg kuersetin/g } \\
\text { kuru örnek) } \\
\text { TFL (mg } \\
\text { quercetin/g dry } \\
\text { sample) }\end{array}$ & $\begin{array}{c}\text { AK } \\
\text { (mM Trolox } / g \\
\text { kuru örnek) } \\
\text { AC } \\
\text { (mM Trolox } / g d r y \\
\text { sample) }\end{array}$ \\
\hline 1 & $55(0)$ & $65(0)$ & 20000 & 134.88 & 86.05 & 17.52 \\
\hline 2 & $30(-1)$ & $65(0)$ & 20000 & 130.05 & 83.31 & 16.91 \\
\hline 3 & $55(0)$ & $65(0)$ & 11200 & 126.92 & 81.16 & 16.45 \\
\hline 4 & $30(-1)$ & $120(+1)$ & 3600 & 96.04 & 61.90 & 12.56 \\
\hline 5 & $55(0)$ & $65(0)$ & 3600 & 115.94 & 74.29 & 15.01 \\
\hline 6 & $55(0)$ & $65(0)$ & 11200 & 128.61 & 82.44 & 16.70 \\
\hline 7 & $55(0)$ & $65(0)$ & 20000 & 133.07 & 85.35 & 17.32 \\
\hline 8 & $30(-1)$ & $10(-1)$ & 3600 & 81.93 & 52.29 & 10.67 \\
\hline 9 & $55(0)$ & $10(-1)$ & 3600 & 80.00 & 51.30 & 10.36 \\
\hline 10 & $55(0)$ & $65(0)$ & 11200 & 125.23 & 80.28 & 16.24 \\
\hline 11 & $80(+1)$ & $65(0)$ & 11200 & 66.24 & 42.52 & 8.88 \\
\hline 12 & $30(-1)$ & $120(+1)$ & 11200 & 103.15 & 66.26 & 13.38 \\
\hline 13 & $80(+1)$ & $120(+1)$ & 20000 & 63.95 & 40.89 & 8.26 \\
\hline 14 & $55(0)$ & $10(-1)$ & 11200 & 92.06 & 58.99 & 11.69 \\
\hline 15 & $80(+1)$ & $65(0)$ & 3600 & 60.58 & 37.80 & 7.86 \\
\hline 16 & $55(0)$ & $65(0)$ & 3600 & 114.73 & 73.53 & 14.86 \\
\hline 17 & $55(0)$ & $65(0)$ & 3600 & 116.06 & 74.64 & 15.17 \\
\hline 18 & $80(+1)$ & $10(-1)$ & 20000 & 40.55 & 25.93 & 5.50 \\
\hline 19 & $55(0)$ & $120(+1)$ & 20000 & 116.66 & 74.81 & 15.12 \\
\hline 20 & $55(0)$ & $65(0)$ & 3600 & 110.51 & 70.97 & 14.55 \\
\hline 21 & $30(-1)$ & $10(-1)$ & 20000 & 105.45 & 67.31 & 13.89 \\
\hline 22 & $55(0)$ & $65(0)$ & 20000 & 136.33 & 87.44 & 17.57 \\
\hline 23 & $55(0)$ & $120(+1)$ & 11200 & 112.20 & 71.56 & 14.55 \\
\hline 24 & $80(+1)$ & $120(+1)$ & 11200 & 65.88 & 42.63 & 8.47 \\
\hline 25 & $80(+1)$ & $120(+1)$ & 3600 & 56.96 & 36.23 & 7.45 \\
\hline 26 & $30(-1)$ & $65(0)$ & 11200 & 122.69 & 78.66 & 15.94 \\
\hline 27 & $30(-1)$ & $65(0)$ & 3600 & 105.69 & 67.66 & 13.89 \\
\hline 28 & $55(0)$ & $10(-1)$ & 20000 & 102.43 & 65.10 & 13.33 \\
\hline 29 & $30(-1)$ & $120(+1)$ & 20000 & 104.00 & 65.27 & 13.53 \\
\hline 30 & $80(+1)$ & $10(-1)$ & 3600 & 21.01 & 12.31 & 2.49 \\
\hline 31 & $55(0)$ & $65(0)$ & 20000 & 135.36 & 86.51 & 17.67 \\
\hline 32 & $80(+1)$ & $10(-1)$ & 11200 & 32.83 & 19.59 & 4.12 \\
\hline 33 & $80(+1)$ & $65(0)$ & 20000 & 73.72 & 47.58 & 9.70 \\
\hline 34 & $55(0)$ & $65(0)$ & 11200 & 125.11 & 80.92 & 16.45 \\
\hline 35 & $30(-1)$ & $10(-1)$ & 11200 & 89.04 & 56.77 & 11.38 \\
\hline 36 & $55(0)$ & $120(+1)$ & 3600 & 104.72 & 67.71 & 13.63 \\
\hline 37 & $55(0)$ & $65(0)$ & 11200 & 124.38 & 79.18 & 16.19 \\
\hline 38 & $55(0)$ & $65(0)$ & 3600 & 113.05 & 72.72 & 14.66 \\
\hline 39 & $55(0)$ & $65(0)$ & 20000 & 135.12 & 88.26 & 17.47 \\
\hline
\end{tabular}

TFM: Toplam Fenolik Madde, TFL: Toplam Flavonoid, AK: Antioksidan Kapasite TPC: Total Phenolic Compounds, TFL: Total Flavonoid, AC: Antioxidant Capacity 
Çizelge 2. Lineer, kuadratik ve interaksiyon terimlerinin etkisini gösteren ANOVA tablosu Table 2. ANOV A table representing the effect of linear, quadratic and interaction terms

\begin{tabular}{|c|c|c|c|c|c|c|c|c|c|c|}
\hline \multirow{3}{*}{$\begin{array}{l}\text { Varyasyon } \\
\text { Kaynağ1 } \\
\text { Source }\end{array}$} & \multirow{3}{*}{$\begin{array}{l}\text { SD } \\
D F\end{array}$} & \multicolumn{3}{|c|}{ Kareler Toplam } & \multicolumn{3}{|c|}{$\begin{array}{c}\text { F Değeri } \\
\text { F V alue }\end{array}$} & \multicolumn{3}{|c|}{$\begin{array}{c}P \text { - Değeri } \\
P \text { - Value }\end{array}$} \\
\hline & & TFM & TFL & AK & TFM & TFL & AK & TFM & TFL & $\mathrm{AK}$ \\
\hline & & TPC & TFL & $A C$ & TPC & TFL & $A C$ & TPC & TFL & $A C$ \\
\hline $\begin{array}{l}\text { Model } \\
\text { Model }\end{array}$ & 11 & 35245.9 & 14823.6 & 599.4 & 567.4 & 492.9 & 747.9 & $<0.0001$ & $<0.0001$ & $<0.0001$ \\
\hline $\mathrm{X}_{1}$ & 1 & 11567.5 & 4800.0 & 196.2 & 2048.3 & 1755.6 & 2692.9 & $<0.0001$ & $<0.0001$ & $<0.0001$ \\
\hline $\mathrm{X}_{2}$ & 1 & 1765.7 & 769.2 & 30.8 & 312.7 & 281.3 & 422.0 & $<0.0001$ & $<0.0001$ & $<0.0001$ \\
\hline $\mathrm{X}_{3}$ & 2 & 2133.0 & 878.2 & 36.3 & 188.9 & 160.6 & 249.1 & $<0.0001$ & $<0.0001$ & $<0.0001$ \\
\hline $\mathrm{X}_{1} \mathrm{X}_{2}$ & 1 & 358.8 & 167.8 & 6.1 & 63.5 & 61.4 & 83.4 & $<0.0001$ & $<0.0001$ & $<0.0001$ \\
\hline $\mathrm{X}_{1} \mathrm{X}_{3}$ & 2 & 23.0 & 3.3 & 0.3 & 2.0 & 0.6 & 1.9 & 0.1507 & 0.5582 & 0.1657 \\
\hline $\mathrm{X}_{2} \mathrm{X}_{3}$ & 2 & 139.7 & 70.7 & 3.4 & 12.4 & 12.9 & 23.3 & 0.0002 & 0.0001 & $<0.0001$ \\
\hline $\mathrm{X}_{1}^{2}$ & 1 & 7846.3 & 3315.3 & 128.5 & 1389.4 & 1212.5 & 1764.1 & $<0.0001$ & $<0.0001$ & $<0.0001$ \\
\hline $\mathrm{X}_{2}^{2}$ & 1 & 4228.5 & 1785.2 & 75.5 & 748.8 & 652.9 & 1035.8 & $<0.0001$ & $<0.0001$ & $<0.0001$ \\
\hline $\begin{array}{l}\text { Kalintı } \\
\text { Residual } \\
\text { Model }\end{array}$ & 27 & 152.5 & 73.8 & 2.0 & & & & & & \\
\hline $\begin{array}{l}\text { Uygunsuzluğu } \\
\text { Lack of Fit }\end{array}$ & 15 & 113.6 & 54.3 & 1.5 & 2.3 & 2.22 & 2.4 & 0.0723 & 0.0849 & 0.0641 \\
\hline $\begin{array}{l}\text { Saf Hata } \\
\text { Pure Error }\end{array}$ & 12 & 38.9 & 19.5 & 0.5 & & & & & & \\
\hline $\begin{array}{l}\text { Toplam } \\
\text { Total }\end{array}$ & 38 & 35398.4 & 14897.5 & 601.3 & & & & & & \\
\hline
\end{tabular}

$\mathrm{X}_{1}$ : Ekstraksiyon sıcaklığı $\left({ }^{\circ} \mathrm{C}\right), \mathrm{X}_{2}$ : Ekstraksiyon süresi (dak), $\mathrm{X}_{3}$ : Karışıtırma hızı (rpm), TFM: Toplam fenolik madde, TFL: Toplam Flavonoid, AK: Antioksidan kapasite, SD: Serbestlik derecesi

$X_{1}$ : Extraction temperature $\left({ }^{\circ} \mathrm{C}\right), X_{2}$ : Extraction time (min), $X_{3}$ : Agitation rate (rpm), TPC: Total phenolic compounds, TFL: Total flavonoid, AC: Antioxidant capacity, DF: Degrees of freedom

Çizelge 3. Ekstraksiyon modeli için elde edilen istatistiksel parametreler

Table 3. Statistical parameters for the extraction model

\begin{tabular}{lccc}
\hline Parametre & TFM & TFL & AK \\
Parameter & TPC & TFL & AC \\
\hline $\mathrm{R}^{2}$ & 0.9957 & 0.9950 & 0.9967 \\
Düz-R ${ }^{2}$ & 0.9939 & 0.9930 & 0.9954 \\
Adj- $\mathrm{R}^{2}$ & & & \\
Yeterli Tahminleme & 86.108 & 80.930 & 99.744 \\
Adequate Precision & 397.55 & 189.54 & 5.11 \\
PRESS & 2.37 & 2.58 & 2.07 \\
C.V. $(\%)$ & $\mathrm{N}$ & & \\
\hline
\end{tabular}

TFM: Toplam fenolik madde, TFL: Toplam Flavonoid, AK: Antioksidan kapasite, Düz-R²: Düzeltilmiş R², PRESS: Tahminlenmiş kalıntı hata kareler toplamı, C.V. (\%): Varyasyon katsayısı

TPC: Total phenolic compounds, TFL: Total flavonoid, AC: Antioxidant capacity, Adj- R²: Adjusted R², PRESS: Predicted residual error sum of squares, C.V. (\%): Coefficient of Variation 
Şekil 1'de ekstraksiyon sıcaklı̆gının artması ile birlikte TFM, TFL ve AK değerlerinin azaldığ1 görülmektedir. TFM içeriğinin azalmasına paralel olarak TFL ve AK değerleri de azalmıştır. Böylelikle TFL ve AK üzerine sıcaklığın etkisi, TFM için elde edilen sonuçlar ile benzerlik göstermiştir. Bu doğrultuda TFM, TFL ve AK için en yüksek değerlerin elde edildiği noktalar

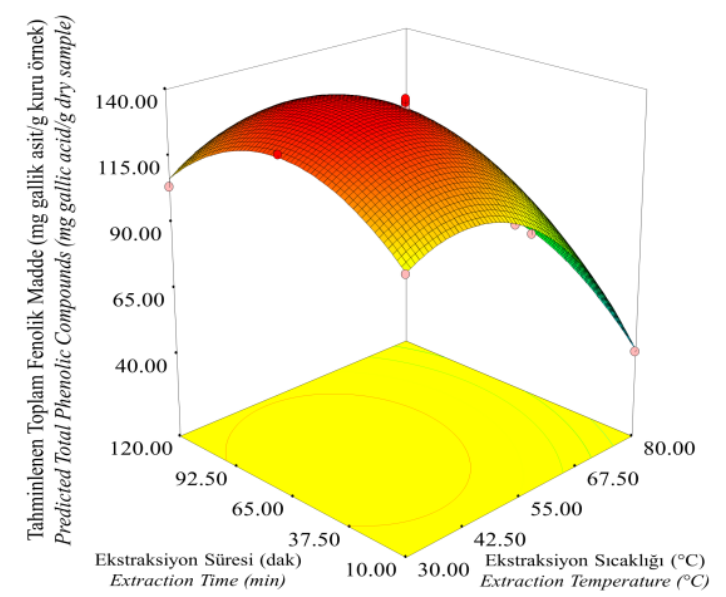

(a)

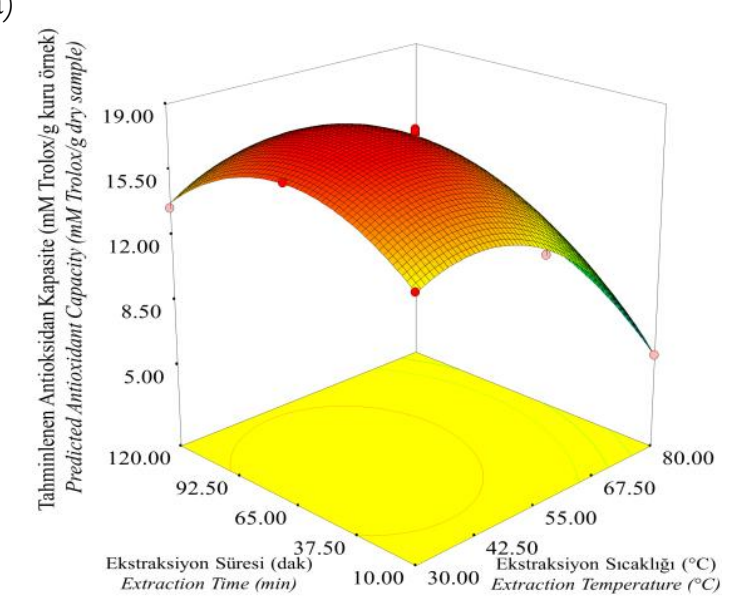

(c) birbirine oldukça yakındır. Şekil 2'de ise TFM, TFL ve AK için elde edilen deneysel veriler ile oluşturulan polinomiyal modellerden tahminlenen veriler kıyaslanmış ve verilerin $45^{\circ}$ doğrusu üzerinde toplandığ görülmüştür. $\mathrm{Bu}$ durum, oluşturulan üç farklı modelin de uygunluğunu desteklemektedir.

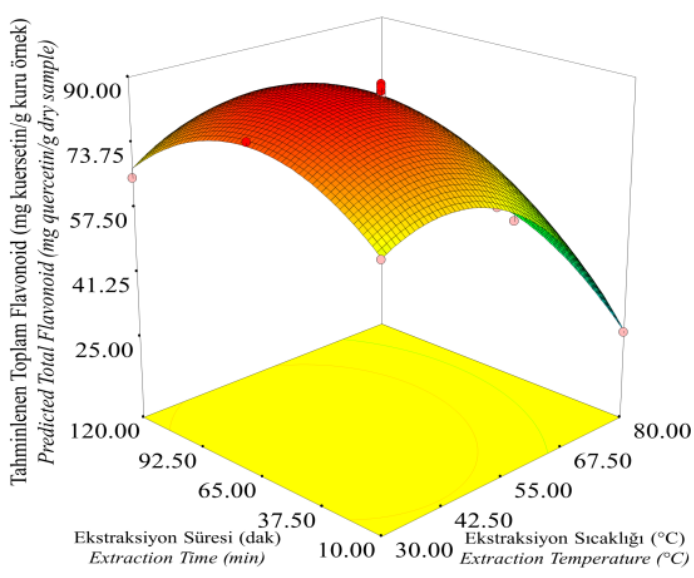

(b)

Şekil 1. $20000 \mathrm{rpm}$ karıştırma hızında ekstraksiyon sıcaklı̆̆ ve ekstraksiyon süresinin etkisini gösteren

3D Yanıt Yüzey Grafikleri: (a) toplam fenolik madde (b) toplam flavonoid (c) antioksidan kapasite Figure 1. 3D Response Surface Graphs showing the effects of temperature and time at $20000 \mathrm{rpm}$ of agitation rate: (a) total phenolic compounds, (b) total flavonoid, (c) antioxidant capacity 


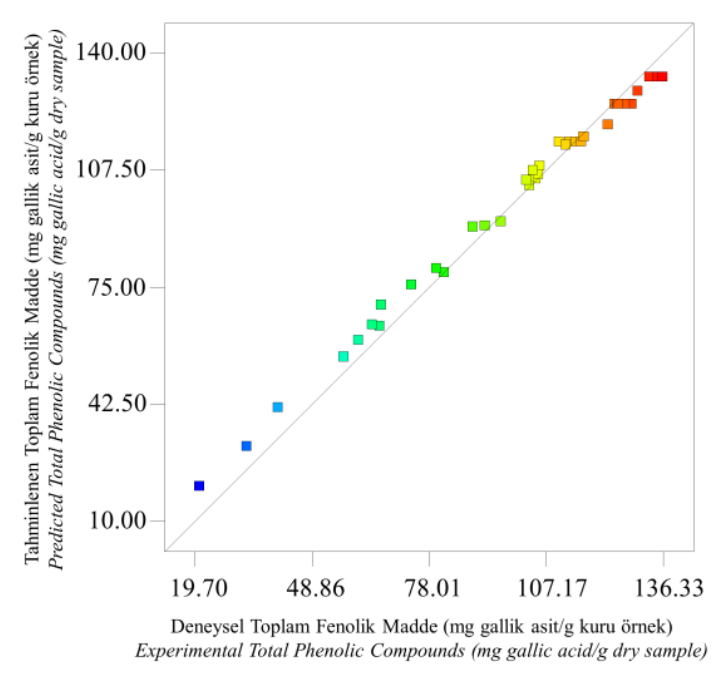

(a)

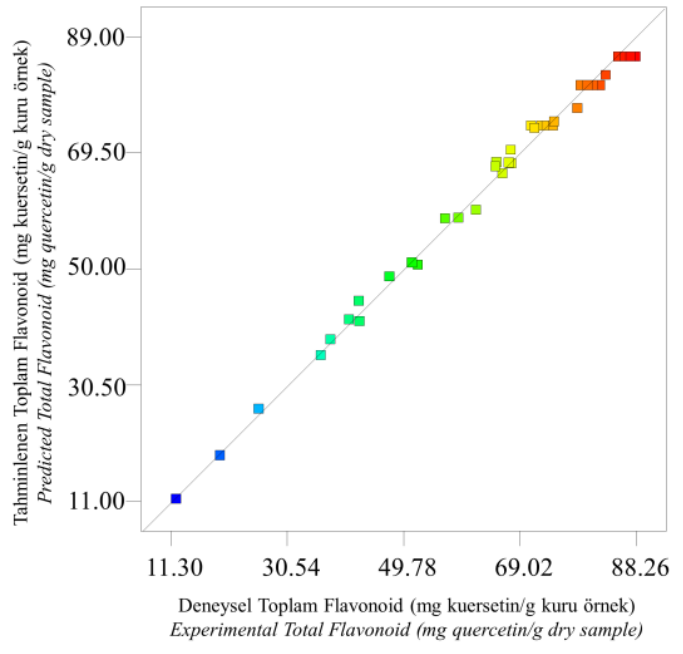

(b)

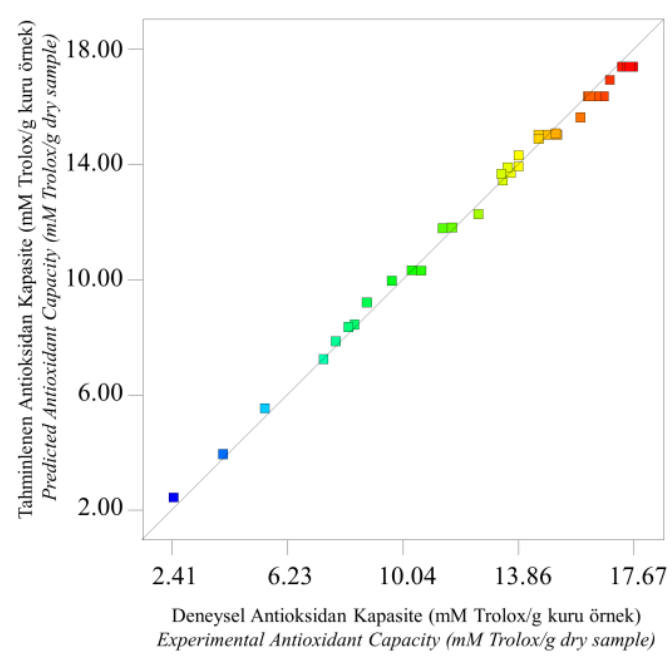

(c)

Şekil 2. Deneysel veriler ile tahminlenen veriler arasındaki ilişki: (a) toplam fenolik madde (b) toplam flavonoid (c) antioksidan kapasite

Figure 2. The relationship between experimental and estimated values: (a) total phenolic compounds, (b) total flavonoid, (c) antioxidant capacity

3D Yanıt Yüzey Grafiğinde gösterildiği gibi, yanıt olarak seçilen TFM, TFL ve AK değerlerinin tümünün en yüksek oranda sağlanabileceği koşul için nümerik optimizasyon çalışması yapılmıştır. Design Expert 7.0 paket programı kullanılarak 'desirability' fonksiyonu yaklaşımına göre optimum noktayı veren ve birbirine yakın 11 adet çözüm belirlenmiştir. Elde edilen bu çözümlerden $45^{\circ} \mathrm{C}$ ekstraksiyon sicaklığ1, 65 dakika ekstraksiyon süresi ve $20000 \mathrm{rpm}$ karıştırma hızı ekstraksiyon işlemi için optimum işlem koşulları olarak belirlenmiştir. Bu noktada TFM, TFL ve AK değerleri sırası ile $139.04 \mathrm{mg}$ gallik asit/g kuru örnek, $89.09 \mathrm{mg}$ kuersetin/g kuru örnek ve 18.11 $\mathrm{mM}$ Trolox/g kuru örnek olarak tahminlenmiştir. TFM, TFL ve AK için üç tekrarlı gerçekleştirilen optimum nokta doğrulama denemelerine göre değerler sırası ile $137.37 \pm 1.87 \mathrm{mg}$ gallik asit/g kuru örnek, $86.96 \pm 1.44 \mathrm{mg}$ kuersetin/g kuru örnek ve 18.11 $\pm 0.55 \mathrm{mM}$ Trolox/g kuru örnek 
olarak tespit edilmiştir. Tahminlenen ve deneysel veriler arasında istatistiksel olarak önemli bir fark olup olmadığ1 ise tek örnek t-testi ile tespit edilmiş, değerler arasında istatistiksel bir fark bulunmadığ1 görülmüştür $(P>0.05)$.

Bu çalışma ile çemen otu tohumundan mekanik karıştırma işlemi ile fenolik ekstraktlar elde edilmiş, işlem koşullarının (ekstraksiyon sıcaklığı, ekstraksiyon süresi ve karıştırma hızı) ekstraksiyona etkisi belirlenerek bu parametrelerin en yüksek TFM, TFL ve AK değerlerinin elde edildiği noktada optimizasyonu sağlanmıştır. Sonuçlara göre seçilen işlem değişkenleri ekstraktların TFM, TFL ve AK değerlerini önemli oranda etkilemişlerdir. Çemen otu tohumundan elde edilen ekstraktların yüksek fenolik madde içeriği ve antioksidan aktivitesi ile gida endüstrisi için önemli bir doğal antioksidan kaynağ olabileceği düşünülmektedir. Çözgen olarak yalnızca saf su kullanılarak üretilen ve karmassık sistemler gerektirmeyen bu ekstraktların üretimi ve optimizasyonu, ilerleyen zamanlarda ürünün model gidalarda kullanilmasina fayda sağlayabilecektir.

\section{ÇIKAR ÇATIŞMASI BEYANI}

Yazarlar, bu makale ile ilgili çıkar çatışması olmadığını beyan eder.

\section{YAZAR KATKILARI}

Sedanur DAŞTAN ve İzzet TÜRKER analizlerin gerçekleştirilmesi, sonuçların istatistiksel analizi ve makalenin yazım aşamalarında; Hilal İşLEROĞLU fikir, tasarım, yöntem, danışmanlık ve makalenin yazım aşamalarında katkı sağlamıştır. Makalenin son hali tüm yazarlar tarafindan okunarak onaylanmışır.

\section{TEŞEKKÜR}

Bu çalışma, Tokat Gaziosmanpaşa Üniversitesi Bilimsel Araştırma Projeleri Koordinatörlüğü (Proje No: 2020/125) tarafindan maddi olarak desteklenmiştir.

\section{KAYNAKLAR}

Abdelgani, M.E., Elsheikh, E.A.E, Mukhtar, N.O. (1999). The effect of rhizobium inoculation and chemical fertilization on seed quality of fenugreek. Food Chem, 64(3): 289-293, doi: 10.1016/S0308-8146(98)00098-3.

Al-Juhaimi, F., Adiamo, O.Q., Ghafoor, K., Babiker, E.E. (2016). Optimization of ultrasonicassisted extraction of phenolic compounds from fenugreek (Trigonella foenum-graecum L.) seed. CyTA-J Food, 14(3): 369-374, doi: 10.1080/19476337.2015.1110202.

Atak, E., Uslu, M.E. (2018). Fenolik bileşikler, ekstraksiyon metotları ve analiz yöntemleri. MCBÜ Soma Meslek Yüksekokulu Teknik Bilimleri Dergisi, 27(3): 40-48.

Ballard, T.S., Mallikarjunan, P., Zhou, K., O'Keefe, S.F. (2009). Optimizing the extraction of phenolic antioxidants from peanut skins using response surface methodology. J Agric Food Chem, 57(8): 3064-3072, doi: 10.1021/jf8030925.

Baytop, T. (1984). Türkiye'de bitkiler ile tedavi. İstanbul Üniversitesi Eczacullk Fakültesi Yayınlar No: 3255, İstanbul.

Belguith-Hadriche, O., Bouaziz, M., Jamoussi, K., Simmonds, M. S., El Feki, A., Makni-Ayedi, F. (2013). Comparative study on hypocholesterolemic and antioxidant activities of various extracts of fenugreek seeds. Food Chem, 138(2-3): 1448-1453, doi: 10.1016/j.foodchem.2012.11.003.

Benmeziane, F., Djamai, R., Cadot, Y., Seridi, R. (2014). Optimization of extraction parameters of phenolic compounds from Algerian fresh table grapes, (Vitis Vinifera). Int Food Res J, 21(3): 10251029.

Birman, H. (2012). Bioactivities of plant flavonoids and the possible action mechanisms. $J$ Ist Faculty Med, 75(3): 46-49.

Brand-Williams, W., Cuvelier, M.E., Berset, C.L.W.T. (1995). Use of a free radical method to evaluate antioxidant activity. LWT-Food Sci Technol, 28(1): 25-30, doi: 10.1016/S00236438(95)80008-5.

Claus, T., Maruyama, S.A., Palombini, S.V., Montanher, P.F., Bonafé, E.G., Junior, O.D.O.S., Matsushita, M., Visentainer, J.V. (2015). Chemical characterization and use of artichoke parts for protection from oxidative stress in canola oil. 
LWT-Food Sci Technol, 61(2): 346-351, 10.1016/j.lwt.2014.12.050.

Dixit, P., Ghaskadbi, S., Mohan, H., Devasagayam, T.P. (2005). Antioxidant properties of germinated fenugreek seeds. Phytother Res, 19(11): 977-983, doi: 10.1002/ptr.1769.

Dorta, E., Lobo, M. G., Gonzalez, M. (2012). Reutilization of mango byproducts: study of the effect of extraction solvent and temperature on their antioxidant properties. J Food Sci, 77(1): C80C88, doi: 10.1111/j.1750-3841.2011.02477.x.

Gaafar, A.A., Salama, Z.A. (2013). Phenolic compounds from artichoke (Cynara scolymus L.) by-products and their antimicrobial activities. $J$ Biol Agric Healthcare, 3(12): 1-6.

Goli, A.H., Barzegar, M., Sahari, M.A. (2005). Antioxidant activity and total phenolic compounds of pistachio (Pistachia vera) hull extracts. Food Chem, 92(3): 521-525, doi: 10.1016/j.foodchem.2004.08.020.

Gökçe, Z., Efe, L. (2016). Çemen (Trigonella foenum-graecum L.) bitkisinin kullanım alanlar1 ve tıbbi önemi. Nevssehir Bilim ve Teknoloji Dergisi, 5: 355-363, doi: 10.17100/nevbiltek.210988.

Gupta, R., Nair, S. (1999). Antioxidant flavonoids in common Indian diet. South Asian Journal of Preventive Cardiology, 3: 83-94.

Hakkinen, S. (2000). Flavonols and fenolic acids in berries and berry products. Doctoral Thesis. Kuopio University Publications D. Medical Sciences. 90 p.

Ignat, I., Volf, I., Popa, V.I. (2011). A critical review of methods for characterisation of polyphenolic compounds in fruits and vegetables. Food Chem, 126(4): 1821-1835, doi: 10.1016/j.foodchem.2010.12.026.

Kenny, O., Smyth, T. J., Hewage, C. M., Brunton, N. P. (2013). Antioxidant properties and quantitative UPLC-MS analysis of phenolic compounds from extracts of fenugreek (Trigonella foenum-graecum) seeds and bitter melon (Momordica charantia) fruit. Food Chem, 141(4): 4295-4302, doi: 10.1016/j.foodchem.2013.07.016.
Khorshidian, N., Yousefi Asli, M., Arab, M., Adeli Mirzaie, A., Mortazavian, A. M. (2016). Fenugreek: potential applications as a functional food and nutraceutical. Nutr Food Sci Res, 3(1): 516.

Mokrani, A., Madani, K. (2016). Effect of solvent, time and temperature on the extraction of phenolic compounds and antioxidant capacity of peach (Prunus persica L.) fruit. Sep PurifTechnol, 162: 68-76, doi: 10.1016/j.seppur.2016.01.043.

Myers, R.H., Montgomery, D.C. (eds.) (1995). Response Surface Methodology, Process and Product Optimization Using Designed Experiments, 2nd ed. John Wiley and Sons, New York, USA, 700 p.

Silva, E.M., Rogez, H., Larondelle, Y. (2007). Optimization of extraction of phenolics from Inga edulis Leaves using response surface methodology. Sep Purif Technol, 55(3): 381-387, doi: 10.1016/j.seppur.2007.01.008.

Srinivasan, K. (2006). Fenugreek (Trigonella foenumgraecum): A review of health beneficial physiological effects. Food Rev Int, 22(2): 203-224, doi: 10.1080/87559120600586315.

Sun, Y., Xu, W., Zhang, W., Hu, Q., Zeng, X. (2011). Optimizing the extraction of phenolic antioxidants from kudingcha made from Ilex kudingcha C.J. Tseng by using response surface methodology. Sep Purif Technol, 78(3): 311-320, doi: 10.1016/j.seppur.2011.01.038.

Tenderis, B. (2010). Üzüm çekirdeğinden fenolik madde ekstraksiyonu (Yüksek Lisans Tezi), Kimya Mühendisliği Anabilim Dalı, 1-62.

Yadav, R., Chowdhury, P. (2017). Screening the Antioxidant activity of Trigonella Foenum graecum seeds. International Joumal of Pharmaceutical Research and Applications, 2(1): 65-70.

Yang, B., Liu, X., Gao, Y. (2009). Extraction optimization of bioactive compounds (crocin, geniposide and total phenolic compounds) from gardenia (gardenia jasminoides ellis) fruits with response surface methodology. Innov Food Sci Emerg Technol, 10(4): 610-615, doi: 10.1016/j.ifset.2009.03.003.

Yim, H.S., Chye, F.Y., Koo, S.M., Matanjun, P., How, S.E., Ho, C.W. (2011). Optimization of 
extraction time and temperature for antioxidant activity of edible wild mushroom, Pleurotus porrigens. Food Bioprod Process, 90(2): 235-242, doi: 10.1016/j.fbp.2011.04.001.

Zuorro, A., Maffei, G., Lavecchia, R. (2016). Reuse potantial of artichoke (Cynara scolymus L.) waste for the recovery of phenolic compounds and bioenergy. J Clean Prod, 111, Part A: 279-284, doi: 10.1016/j.jclepro.2015.06.01. 